$597.556 .334 .1: 591.336(265.53)$

\title{
ЭМБРИОНАЛЬНОЕ И РАННЕЕ ЛИЧИНОЧНОЕ РАЗВИТИЕ БУРОГО TEPПУГA HEXAGRAMMOS OCTOGRAMMUS (SCORPENIFORMES: HEXAGRAMMIDAE) СЕВЕРНОЙ ЧАСТИ ОХОТСКОГО МОРЯ
}

\author{
Юсупов Р. Р., Юсупов Рус. Р. \\ ФГБУН Институт биологических проблем Севера (ИБПС) ДВО РАН, г. Магадан \\ E-mail: ryusupov_mag@mail.ru
}

\begin{abstract}
Проведена инкубация икры бурого терпуга Heхagrammos octogrammus северной части Охотского моря в эксперименте. Дано детальное описание морфологии развития вида от момента оплодотворения икры до перехода личинок на внешнее питание, сопровождаемое микрофотографиями икринок и личинок в прижизненном состоянии. Установлено, что оплодотворенные икринки $H$. octogrammus северной части Охотского моря имеют диаметр 1.75 мм при колебаниях 1.61-1.98 мм. При средней температуре $11.5^{\circ} \mathrm{C}$ вылупление эмбрионов происходит через 33.5 сут инкубации. Вылупившиеся предличинки имеют длину TL (Total length) 7.78 мм (7.15-8.06 мм) и SL (Standard length) 7.39 мм (6.83-7.68 мм). При достижении TL 8.74 мм (8.14-9.26 мм) и SL 8.21 мм (7.63-8.86 мм) личинки переходят на внешнее питание. Выявлены региональные особенности пигментации бурого терпуга в раннем онтогенезе.
\end{abstract}

Ключевые слова: бурый терпуг Hexagrammos octogrammus, эмбриональное развитие, предличинка, личинка, северная часть Охотского моря.

DOI: 10.34078/1814-0998-2021-1-89-100

\section{ВВЕДЕНИЕ}

Бурый терпуг Hexagrammos octogrammus (Pallas, 1810) широко распространен в водах северотихоокеанского побережья от Берингова моря и Алеутских островов до Японского моря (Рутенберг, 1962; Quast, 1964; Линдберг, Красюкова, 1987; Mecklenburg et al., 2016). Среди обитающих в северной части Охотского моря представителей Hexagrammidae $H$. octogrammus достигает высокой численности, уступая в этом отношении лишь пятнистому терпугу H. stelleri Tilesius, 1810.

В работах ряда исследователей широко освещены особенности экологии, биологической структуры, роста, созревания, нерестового поведения бурого терпуга, а также его естественной гибридизации с другими видами Hexagrammidae (Горбунова, 1962; Kendall, Vinter, 1984; Munehara et al., 1987, 2000; Gomelyuk, Leunov, 1999; Антоненко, Гнюбкина, 2001; Черешнев и др., 2001; Антоненко, Пущина, 2002; Федоров и др., 2003; Шестаков, Назаркин, 2006; Karen et al., 2007; Шестаков, Грунин, 2018).

Сведений об эмбриональном периоде жизни бурого терпуга не так много. В работе Н. Н. Горбуновой (1962) впервые были представлены рисунки нескольких икринок бурого терпуга на разных стадиях развития, собранных автором в 1958 г. на нерестилище в бух. Тафуин (ныне бух.

(C) Юсупов Р. Р., Юсупов Рус. Р., 2021
Южно-Морская) Японского моря. Некоторые сведения по эмбриональному развитию бурого терпуга зал. Петра Великого Японского моря содержатся в работе Д. В. Антоненко и В. П. Гнюбкиной (2001). Однако вследствие краткости изложения и отсутствия иллюстративного материала нет полного представления об этом важном периоде в жизненном цикле вида.

Цель проведенных исследований - дать детальное описание морфогенеза $H$. octogrammus северной части Охотского моря с фиксацией сроков и темпов прохождения этапов его эмбрионального и раннего постэмбрионального развития до перехода на внешнее питание, достаточного для сравнительного анализа с представителями вида других районов обитания и определения видовой принадлежности при проведении ихтиопланктонных съемок. Наряду с этим, представляет интерес провести сравнительный анализ темпов прохождения стадий и этапов эмбрионального развития бурого терпуга с аналогичными данными по пятнистому терпугу, сведения о котором опубликованы нами ранее (Юсупов, Юсупов, 2019а).

\section{МАТЕРИАЛ И МЕТОДИКА}

Исследования проведены авторами в июле - августе 2018 г. Текучие производители бурого терпуга были отловлены в Тауйской губе на сублиторали о. Недоразумения (рис. 1, слева). 

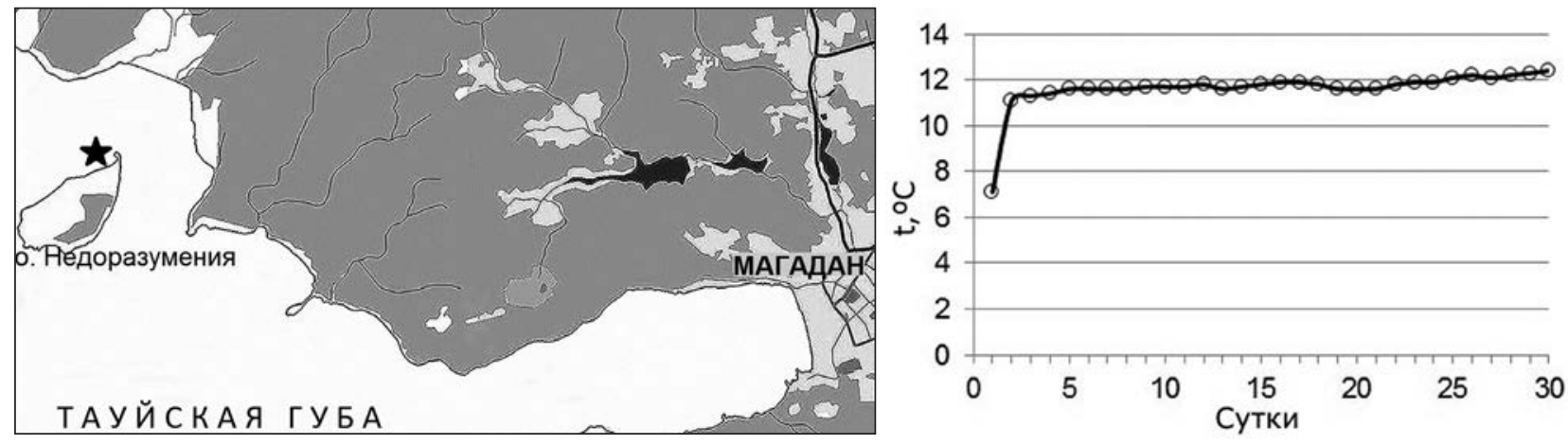

Puc. 1. Карта района исследований (слева) и динамика среднесуточной температуры воды при инкубации икры (справа). Звездочкой отмечен участок отлова бурого терпуга

Fig. 1. Map of the research area (left) and dynamics of mean daily water temperature during incubation of the eggs (right). The asterisk indicates the location site of the masked greenling catch

Лов проводили с помощью обтянутых сетным полотном цилиндрических рыбных ловушек длиной 1 м, диаметром 40 см и входным пространством диаметром 15 см. В качестве наживки использовали свежезамороженную сельдь.

Икринки от 2 готовых к нересту самок были искусственно оплодотворены семенной жидкостью, взятой от 6 самцов. Вскоре после оплодотворения, до затвердевания оболочки яиц и клейкого хориона, и их агрегации в плотную кладку, были отделены 456 неповрежденных икринок, после чего вся икра была доставлена к месту проведения стационарных наблюдений. В период транспортировки температуру воды в емкостях с икрой понижали до $3.1^{\circ} \mathrm{C}$. В дальнейшем инкубация икры проходила в условиях непрерывной аэрации воды при средней температуре $11.5^{\circ} \mathrm{C}$, с максимальным ее прогревом к концу эксперимента до $12.4^{\circ} \mathrm{C}$ (рис. 1, справа). Раз в сутки проводили полную замену воды. Для предотвращения развития грибкового и бактериального обрастания оболочки икры использовали фильтрованную воду. Развитие наблюдали на живом материале в горизонтальной и вертикальной оптической плоскостях сечения с помощью камеры Ж. А. Черняева (1962). При определении этапов и стадий развития руководствовались работой А. П. Макеевой (1992). Сумму тепла $\left({ }^{\circ} \mathrm{C} /\right.$ ч) рассчитывали с учетом динамики температуры в течение инкубации икры. Для наблюдений за ранним онтогенезом вылупляющихся предличинок переводили в аквариум. В процессе исследований проведено 116 серий наблюдений. Иллюстративный материал представлен по результатам микросъемки с помощью цифровой фотокамеры «Rekam Presto 40M» через микроскоп МБС-10.

Все производители бурого терпуга после отбора половых продуктов, а также оставшиеся после эксперимента личинки в прижизненном состоянии возвращены в среду обитания.

\section{РЕЗУЛЬТАТЫ И ОБСУЖДЕНИЕ}

Имеются расхождения в литературных сведениях о сроках размножения бурого терпуга в северной части Охотского моря. По данным И. А. Черешнева с соавторами (2001), размножение этого терпуга происходит в июле - октябре. А. В. Шестаков и С. И. Грунин (2018) указывают, что нерест бурого терпуга на сублиторали Тауйской губы Охотского моря начинается в конце июня и продолжается до конца июля. Проведенный нами в 2018 г. визуальный анализ готовности производителей бурого терпуга к нересту подтвердил информацию А. В. Шестакова и С. И. Грунина (2018). Из отловленных 19-21 июля для отбора половых продуктов 68 взрослых самок лишь две из них имели икру на стадии овуляции, остальные были отнерестившимися.

\section{Эмбриональный период}

Отделенные от общей кладки и развивающиеся свободно демерсальные икринки H. octogrammus имеют диаметр 1.61-1.98 (1.75 \pm 0.01$)$ мм. В северо-восточной части Тихого океана диаметр икринок бурого терпуга варьирует от 1.75 до 2.10 мм (Washington et al., 1983). У побережья о. Хоккайдо и в целом у северного побережья Японии икра этого терпуга имеет размеры 1.80 2.20 мм (Munehara et al., 1987, 2000). По этому признаку наиболее вариабельны икринки бурого терпуга, размножающегося в западной части Японского моря, где их размеры колеблются в пределах 1.75-2.10 мм (Горбунова, 1962) или 1.50-2.00 мм (Антоненко, Пущина, 2002).

Икринки имеют плотную оболочку с легкой волокнистой структурой. Небольшое перевителлиновое пространство (менее $20 \%$ от общего объема яйца) относит их к олигоплазматическому типу. В желтке имеется скопление жировых капель оранжевого цвета. Микропиле в виде воронковидного углубления сохраняется большую часть эмбриогенеза (рис. 2, А). 

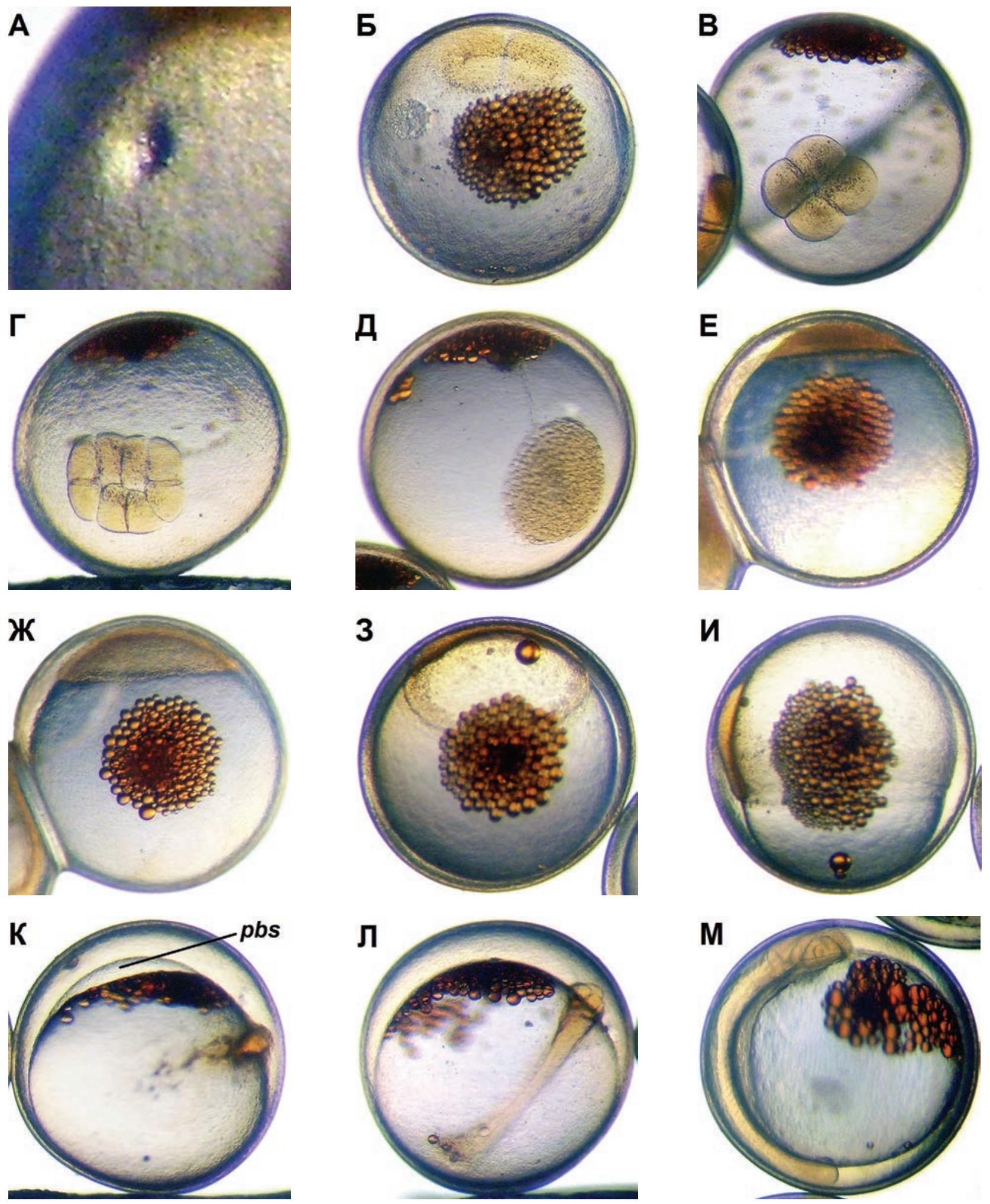

Pис. 2. Эмбриональное развитие бурого терпуга северной части Охотского моря: А - микропиле; Б - стадия 2 бластомеров; $\mathbf{B}$ - стадия 4 бластомеров; $\boldsymbol{\Gamma}$ - стадия 8 бластомеров; Д - крупноклеточная бластула; $\mathbf{E}-$ бластуляция; Ж - эпиболия и гаструляция; $\mathbf{3}$ - зародышевое кольцо; И - зародышевый валик; К - перибластический синус; Л - сегментация тела; М - развитие глазных бокалов и закладка хрусталиков. $p b c-$ перибластический синус

Fig. 2. Embryonic development of the masked greenling in the northern part of the Sea of Okhotsk: A - micropyle; Б - 2-blastomere stage; $\mathbf{B}$ - 4-blastomere stage; $\boldsymbol{\Gamma}$ - 8-blastomere stage; Д - large-celled blastula; $\mathbf{E}$ - blastulation; Ж - epiboly and gastrulation; $\mathbf{3}$ - germinal ring; $И$ - germinal platen; $\mathbf{К ~ - ~ p e r i b l a s t i c ~ s i n u s ; ~ Л ~ - ~ b o d y ~ s e g m e n t a t i o n ; ~}$ $\mathbf{M}$ - development of eye glasses and lenses. $p b c$ - periblastic sinus 
У многих представителей отряда Scorpaeniformes зрелые ооциты агрегированы слизистой массой (Washington et al., 1983; Moser, 1996). Сходная структура кладок икры описана Н. Н. Горбуновой (1962) у H. octogrammus Японского моря. По мнению некоторых исследователей (Moyer, Zaiser, 1981), входящие в состав слизи вещества обладают свойством репеллента, отпугивающего другие виды рыб, способных поедать выметанную икру.

Как и у пятнистого терпуга $H$. stelleri, эмбриональное развитие которого мы наблюдали параллельно с бурым терпугом, зрелая икра $H$. octogrammus агрегирована прозрачной гелеобразной массой. Несмотря на эластичность, эта структура крепко удерживает икринки, затрудняя их извлечение в неповрежденном состоянии. Просмотр кладки икринок через 7 ч после их оплодотворения показал, что гелеобразная оболочка исчезла, а икринки плотно скреплены между собой в объемную сетчатую структуру. Клейкая оболочка хориона икринок бурого терпуга через некоторое время теряет свои адгезивные свойства, и, отделенные от общей кладки, они в дальнейшем не образуют друг с другом агрегаций. Нами также отмечено, что на завершающих стадиях эмбриогенеза, с развитием у эмбрионов желез вылупления, сцепление между икринками ослабевает, и их агрегация распадается при механическом воздействии, что, по всей видимости, облегчает выход эмбрионов из глубоких слоев кладки.

По литературным данным (Горбунова, 1962; Munehara et al., 1987; Шестаков, Грунин, 2018), общая окраска икры H. octogrammus определяется цветом желтка и оболочки и может иметь как коричневато-лиловый, так и прозрачный синий цвет. Желток чаще имеет голубоватую окраску, но может быть светлым, желтоватым. Оболочка толстая, плотная, коричневой окраски. Жировые включения окрашены в ярко-красный или оранжевый цвет.

По нашим наблюдениям общая окраска икринок бурого терпуга зависит от степени развития хориона, толщина которого варьирует у разных икринок. Икринки с толстой оболочкой хориона окрашены в светло-коричневый цвет, при слабом его развитии они имеют голубоватый цвет. По этой причине окраска желтка в проходящем свете может характеризоваться голубым, синим или светло-лиловым цветовым тоном.

Вследствие кратковременного понижения температуры воды до $3.1^{\circ} \mathrm{C}$ во время транспортировки до места стационарных наблюдений этап активации икры бурого терпуга был продолжительным и деление зиготы на бластомеры началось через 12 ч после оплодотворения, а весь этап дробления проходил в течение 36 ч (рис. 2, Б-Д). Через 48 ч после оплодотворения эмбрио- ны достигли III этапа бластуляции (см. таблицу; рис. 2, E).

В возрастном интервале 58-120 ч эмбрионы бурого терпуга проходят IV этап гаструляции и эпиболии. В это время последовательно формируются равноплечий валик (66 ч), зародышевое кольцо (83 ч) и зародышевый валик (101 ч) (рис. 2, Ж-И). В процессе эпиболии в области охвата бластодермой поверхности желтка происходит его сжатие. В результате этого желток в поперечном плане приобретает слегка грушевидную форму и восстанавливает свою округлость после завершения эпиболии и замыкания бластопора в возрасте 125 ч. Незадолго до завершения этапа (в возрасте 120 ч) на поверхности желточного мешка эмбрионов бурого терпуга в виде прозрачной куполообразной полости развивается перибластический синус (рис. 2, К). Более подробно процесс развития этого провизорного органа у двух видов терпугов рассмотрен нами в отдельной работе (Юсупов, Юсупов, 2019а). У пятнистого терпуга перибластический синус начинает развиваться уже в конце предыдущего этапа гаструляции и эпиболии (возраст 105 ч), а сам процесс функционирования этого провизорного органа длится дольше, заканчиваясь на стадии хвостовой почки в возрасте 209 ч.

В возрасте 133 ч у эмбрионов бурого терпуга продолжается формирование глазных плакод, в задней части туловищного отдела развивается Купферов пузырек, а спустя 5 ч начинается сегментация тела закладкой первых двух сомитов (рис. 2, Л).

Через 180 ч инкубации V этап эмбриогенеза завершается образованием хвостовой почки. В этом возрасте эмбрион охватывает 50\% окружности желточного мешка. Развившиеся в теменной части головного отдела эмбрионов 4-5 энцефаломеров разделяют общую нервальную трубку на два основных отдела - головной и спинной мозг. Сформированы глазные пузыри, в них хорошо просматриваются контуры развивающихся хрусталиков. В теле насчитывается 17-19 сомитов (рис. 2, М). Функционировавший на $\mathrm{V}$ этапе развития в течение 65 ч перибластический синус в возрасте 185 ч редуцируется. Незадолго до завершения этапа, вдоль дорзальной стороны тела развивается тонкая полоска плавниковой каймы, охватывающая и хвостовую почку.

Возраст 204 ч. Задняя часть тела эмбрионов бурого терпуга начинает отчленяться от желточного мешка с образованием хвостового отдела, и эмбрионы переходят на VI этап развития. В этом возрасте общее число сомитов в теле возрастает до 28-29, из которых 8-9 находятся в хвостовом отделе. Под нервной трубкой на уровне 2-3-го энцефаломера просматриваются хорошо развитые слуховые по- 
Таблища. Этапы и стадии эмбрионального развития H. octogrammus северной части Охотского моря

Table. Stages of embryonic development of $\boldsymbol{H}$. octogrammus in the northern part of the Sea of Okhotsk

\begin{tabular}{|c|c|c|c|c|}
\hline Этап & $\begin{array}{c}\text { Длитель- } \\
\text { ность } \\
\text { этапа, ч }\end{array}$ & Стадия развития & $\begin{array}{c}\text { Возраст, } \\
\text { ч }\end{array}$ & $\mathrm{t},{ }^{\circ} \mathrm{C}$ \\
\hline $\mathrm{I}$ & 12 & Активация икры, образование бластодиска & - & 3.1 \\
\hline \multirow{7}{*}{ II } & \multirow{7}{*}{38} & Дробление: & & \\
\hline & & 2 бластомера & 12 & 4.7 \\
\hline & & 4 бластомера & 14 & 5.5 \\
\hline & & 8 бластомеров & 17 & 6.1 \\
\hline & & 32 бластомера & 22 & 7.1 \\
\hline & & Крупноклеточная бластула & 32 & 11.2 \\
\hline & & Мелкоклеточная бластула & 38 & 11.2 \\
\hline III & 8 & Бластуляция & 50 & 11.2 \\
\hline \multirow{5}{*}{ IV } & \multirow{5}{*}{43} & Гаструляция и эпиболия & 58 & 11.3 \\
\hline & & Эпиболия 20\%, зародышевое кольцо & 83 & 11.4 \\
\hline & & Эпиболия 30\% & 86 & 11.4 \\
\hline & & Эпиболия 50\% & 96 & 11.5 \\
\hline & & Осевой зачаток эмбриона & 98 & 11.4 \\
\hline \multirow{6}{*}{$\mathrm{V}$} & \multirow{6}{*}{103} & Органогенез, зародышевый валик & 101 & 11.5 \\
\hline & & Развитие перибластического синуса & 120 & 11.5 \\
\hline & & Завершение эпиболии & 125 & 11.5 \\
\hline & & Сегментация туловищной мезодермы & 133 & 11.6 \\
\hline & & Развитие Купферова пузырька & 138 & 11.6 \\
\hline & & Формирование хвостовой почки & 168 & 11.6 \\
\hline \multirow{4}{*}{ VI } & \multirow{4}{*}{35} & Отчленение хвостового отдела & 204 & 11.6 \\
\hline & & Подвижное состояние эмбрионов & 209 & 11.7 \\
\hline & & Образование перикардиальной полости & 221 & 11.7 \\
\hline & & Развитие отолитов и пигментация тела & 233 & 11.7 \\
\hline \multirow{9}{*}{ VII } & \multirow{8}{*}{217} & Начало сердечной деятельности & 239 & 11.6 \\
\hline & & Образование гемоглобина в плазме & 273 & 11.6 \\
\hline & & Пигментация глаз меланофорами & 281 & 11.8 \\
\hline & & Образование эритроцитов & 318 & 11.7 \\
\hline & & Развитие подкишечно-желточной вены & 327 & 11.7 \\
\hline & & Образование зачатков грудных плавников & 343 & 11.7 \\
\hline & & Зародыш охватывает желточный мешок & 352 & 11.7 \\
\hline & & Пигментация глаз гуанофорами & 383 & 11.8 \\
\hline & & Отчленение рыла от желточного мешка & 416 & 11.9 \\
\hline \multirow{4}{*}{ VIII } & \multirow{4}{*}{347} & Развитие жаберно-челюстного аппарата & 456 & 11.9 \\
\hline & & Развитие первых желез вылупления & 502 & 11.6 \\
\hline & & Подвижное состояние грудных плавников & 527 & 11.7 \\
\hline & & Вылупление & 803 & 12.3 \\
\hline
\end{tabular}

лости (рис. $3, \mathbf{A})$. Через 5 ч с момента образования хвостового отдела эмбрионы достигают в развитии подвижного состояния, проявляющегося в редких сокращениях срединного участка туловища, при этом хвостовой отдел остается неподвижным.

Возраст 221 ч. С брюшной стороны тела на участке от середины глаза до первой пары сомитов развивается погруженная в желточный ме- шок перикардиальная полость, в которой в дальнейшем формируется сердце (рис. 3, Б). Завершение этапа регистрируется в возрасте 233 ч появлением по бокам задней половины туловища первых меланофоров и развитием отолитов в слуховых капсулах.

Переход эмбрионов бурого терпуга на этап развития эмбриональной сосудистой системы 

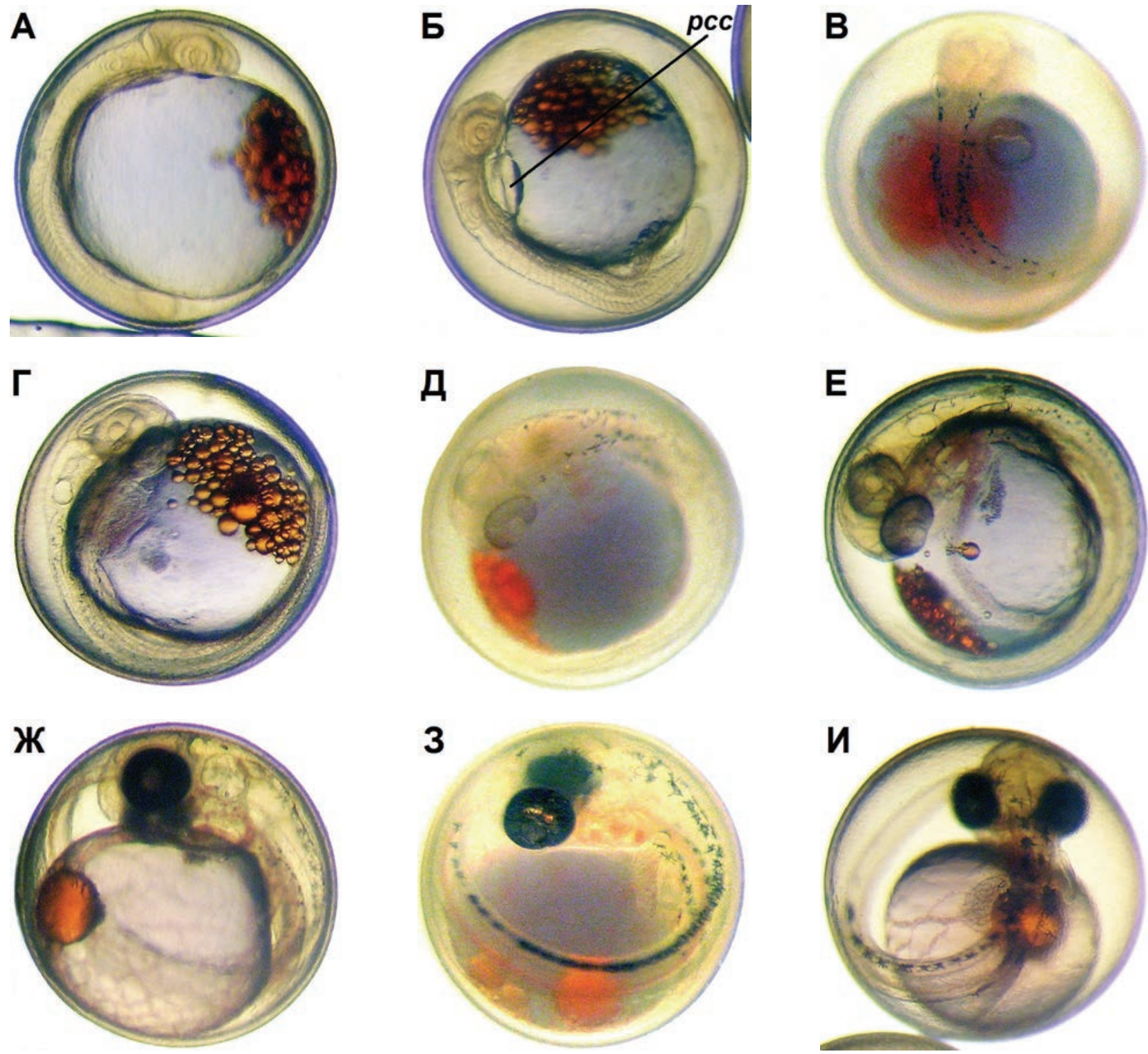

Puc. 3. Эмбриональное развитие бурого терпуга северной части Охотского моря: $\mathbf{A}$ - отчленение хвостового отдела; Б - образование перикардиальной полости; $\mathbf{B}$ - пигментация тела; $\boldsymbol{\Gamma}$ - начало кроветворения; Д - пигментация глаз; $\mathbf{E}$ - развитие подкишечно-желточной вены; Ж - развитие гиоидных дуг; $\mathbf{3}$ - пигментация глаз гуанофорами; И - развитие печени. рсс - перикардиальная полость. На рис. В, Д, $\mathbf{3}$ - вид икринок в падающем свете

Fig. 3. Embryonic development of Masked greenling of the Northern part of the Sea of Okhotsk: A - separation of the caudal division; $\mathbf{6}$ - pericardial cavity formation; $\mathbf{B}$ - body pigmentation; $\boldsymbol{\Gamma}$ - onset of hematopoiesis; Д - eye pigmentation; $\mathbf{E}$ - development of subintestinal yolk vein; $\boldsymbol{Ж}$ - hyoid arc development; $\mathbf{3}$ - eyes pigmentation with guanophores; И - liver development. pcc-pericardial cavity. Panel В, Д, 3 - eggs in incident light

происходит в возрасте 239 ч. Это один из двух самых продолжительных этапов в эмбриональном развитии вида. Он охватывает по времени 217 ч и наступает с началом функционирования сердечной трубки с первоначальной частотой 32-45, в среднем 37 сокращений в минуту.

В возрасте 263 ч интенсивность работы сердца возрастает до 38-52, в среднем 46 пульсаций в минуту. На поверхности тела эмбрионов этого возраста пигментация черными меланофорами распространяется на весь туловищный от- дел. Одновременно происходит их постепенная миграция на дорзальную сторону с образованием парного ряда. При этом ряд крупных звездчатых меланофоров сохраняется в области будущего перитонеума (рис. 3, В).

Наблюдения Ж. А. Черняева (1964) за эмбриональным развитием байкальского омуля и сига показали, что на стадии пульсирующей сердечной трубки, когда еще полностью отсутствует система кровообращения, на желточном мешке появляется специализированный орган кро- 
ветворения и кровенакопления в виде вытянутого треугольного мешочка неправильной формы. Этот мешочек хорошо заметен благодаря большому скоплению форменных элементов крови, окрашенных в красный цвет.

Наши наблюдения показали, что в возрасте 273 ч у эмбрионов бурого терпуга также развивается морфологически сходная структура, обнаруживающая себя под перикардиальной полостью в виде погруженного в желтковую массу образования розового или розовато-фиолетового сквозь желток цвета (рис. $3, \Gamma$ ). Однако в отличие от сиговых рыб, кроветворный мешочек у эмбрионов бурого терпуга содержал лишь окрашенную плазму без форменных элементов, которые развиваются позднее.

Рассматривая процесс кроветворения у костистых рыб, 3. С. Кауфман (1990) отмечал, что у одних видов рыб гемоглобин сразу структурируется в цитоплазме полихроматофильного эритроцита, у других он, возможно, появляется в плазме и лишь затем в эритроцитах. По всей видимости, у H. octogrammus этот процесс происходит по второму типу. Такая же особенность раннего кроветворения установлена нами и у близкого к бурому пятнистого терпуга $H$. stelleri (Юсупов, Юсупов, 2019б).

Стадия пигментации глаз у эмбрионов наступает в возрасте 283 ч (рис. 3, Д). При этом внешний периметр сформированных глазных бокалов окрашивается меланином более интенсивно, чем остальная их поверхность, за исключением хрусталиков, остающихся прозрачными.

В возрасте 318 ч гемоглобин, находящийся до этого в плазме крови в свободном состоянии, начинает структурироваться в образующихся эритроцитах. Еще через 9 ч наблюдается васкуляризация желточного мешка, т. е. развитие на его поверхности сети кровеносных сосудов. Одновременно с этим происходит формирование крупной подкишечно-желточной вены (vena subintestinalis vitellinae), огибающей желточный мешок и соединяющейся в передней его части с кювьеровым протоком, через который, в свою очередь, кровь поступает в предсердие, а позднее - в дифференцирующийся от него венозный синус (рис. 3, E).

С развитием висцеральной системы кровоснабжения развивается пара мандибулярных дуг (435 ч), а затем над ними с дорзальной стороны пара гиоидных дуг, представляющих собой провизорный орган, отвечающий за снабжение глаз кровью до появления дефинитивного кровообращения. Обе они в возрасте 504 ч обнаруживаются в виде овальной структуры позади глаз, под формирующейся жаберной крышкой (рис. 3, Ж). В это же время происходит активное слияние жировых капель в одну или несколь- ко крупных. Глаза плотно пигментированы не только черными меланофорами, но и гуанофорами, отдельные клетки которых на дермальном слое глазных бокалов развиваются еще в возрасте 383 ч. Поэтому в падающем свете черные глазные бокалы приобретают золотистый блеск (рис. 3, 3). Пигментные клетки на дорзальной стороне, образовывавшие до этого вдоль спинной плавниковой складки парный ряд, начинают сливаться в общую пигментную полоску. Это наиболее заметно в задней части туловищного и хвостового отделов.

Возраст 527 ч. У эмбрионов хорошо заметна погруженная в желточный мешок разросшаяся печень губчатой структуры, от которой отходит крупная печеночно-кишечная вена. Кювьеров проток впадает в венозный синус сердца, которое к этому времени уже сместилось на латеральную сторону. Грудные плавники также сместились на латеральную сторону до уровня первого миомера и приобрели подвижность (рис. 3, И).

В процессе VIII этапа продолжается формирование дефинитивных органов. Обращает на себя внимание то, что первые железы вылупления в виде мелких бугорков на головном отделе начинают развиваться еще за 300 ч до завершения эмбриогенеза. Можно предположить, что это обусловлено высокой плотностью внешней оболочки икры и необходимостью длительного секреторного воздействия желез не только на нее, но и для ослабления сцепления икринок между собой. Это особенно важно для облегчения выхода из оболочки яиц тех эмбрионов, развитие которых проходило в глубоких слоях кладки. Наблюдения показали, что жесткое сцепление между икринками постепенно ослабевает и незадолго до вылупления общая агрегация кладки легко разрушается на отдельные икринки при механическом воздействии.

В нашем эксперименте при средней температуре $11.5^{\circ} \mathrm{C}$ эмбриональное развитие бурого терпуга длилось 33 сут и 11 ч. Сумма принятого икринками тепла составила $9417^{\circ} \mathrm{C} /$. Вылупление эмбрионов происходило в течение 2 сут.

Сопоставление данных по срокам прохождения стадий и этапов эмбриогенеза у бурого и пятнистого терпугов показало, что этапы активации икры и дробления плазмодиска у обоих видов происходили синхронно. Первое существенное видовое различие проявилось между ними на стадии образования зародышевого кольца, когда у бурого терпуга это произошло на 21 ч позже, чем у пятнистого терпуга. Такая задержка в его развитии прослеживалась и в дальнейшем. Так, в его икринках перибластический синус начал развиваться на поверхности желтка в возрасте 120 ч, а через 65 ч произошла его редукция. Напротив, у пятнистого терпуга этот провизорный орган по- 
является на 15 ч раньше (возраст 105 ч) и функционирует дольше (104 ч).

В дальнейшем темпы развития бурого терпуга ускоряются. Это подтверждается тем фактом, что этап гаструляции и эпиболии оба вида завершают в близкие сроки, с 5-часовой задержкой у бурого терпуга. Сохраняющийся у эмбрионов этого вида в течение этапа органогенеза более высокий, чем у пятнистого терпуга, темп развития обеспечивает им переход на VI этап отчленения хвостового отдела от желточного мешка на 6 ч раньше.

В целом можно констатировать, что видовые особенности эмбрионального развития бурого и пятнистого терпугов хорошо прослеживаются на сравнительно небольших промежутках времени, соответствующих стадиям развития. На уровне более крупных хронологических промежутков первые 6 этапов эмбриогенеза оба вида терпугов проходят синхронно или в близкие сроки. Задержка в развитии бурого терпуга наиболее ярко проявилась на VII этапе развития эмбриональной сосудистой системы дыхания и в особенности на VIII этапе развития жаберно-челюстного аппарата (рис. 4). Такая задержка в развитии бурого терпуга в целом отразилась на длительности периода эмбриогенеза, который завершился более чем на 3 сут позже, чем у пятнистого терпуга.

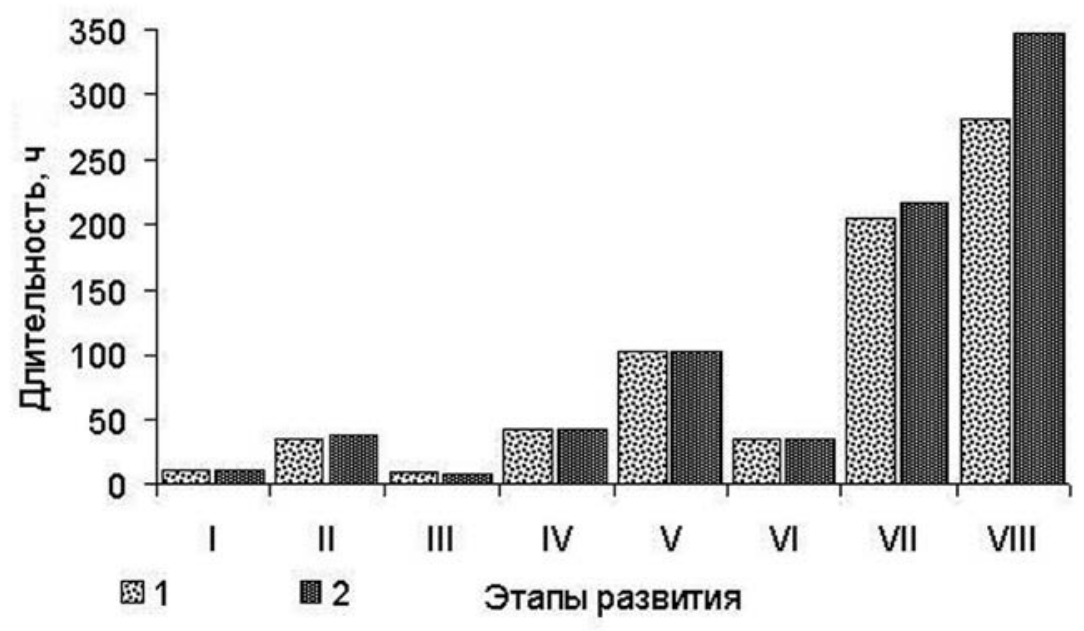

Puc. 4. Длительность этапов эмбрионального развития бурого и пятнистого терпугов в эксперименте: 1 - пятнистый терпуг, 2 - бурый терпуг

Fig. 4. Embryonic development stages duration for the white-spotted and the masked greenlings during the experiment: 1 - white-spotted greenling, 2 - masked greenling

\section{Постэмбриональный период}

Только что освободившиеся от оболочки яиц предличинки пятнистого терпуга имеют общую длину TL (total length) 7.15-8.06 мм (в среднем $7.77 \pm 0.06$ мм) и длину от начала рыла до конца хорды SL (standard length) 6.83-7.68 (в среднем $7.39 \pm 0.06$ мм) (рис. 5,А, Б). В сравнительном плане они крупнее ровесников из других регио- нов. В северо-восточной части Тихого океана бурый терпуг освобождается от оболочки яиц при длине SL 6-7 мм, а их ровесники у побережья о. Кадьяк имеют средний показатель 7 мм (Washington et al., 1983; Kendall, Vinter, 1984). По данным других авторов (Горбунова, 1962; Антоненко, Пущина, 2002), в Японском море предличинки бурого терпуга вылупляются при общей длине TL 6-7 мм.

Только что вылупившиеся предличинки бурого терпуга морфофункционально хорошо развиты. Кровеносная система частично сохраняет эмбриональный тип циркуляции крови на желточном мешке, но быстро редуцируется. Размер жаберных крышек достигает $2 / 3$ диаметра глаза. У большинства предличинок челюстной аппарат характеризуется подвижной нижней челюстью. Печень продолжает оставаться погруженной в желточный мешок. Формирующаяся прямая кишка и анус вычленяют из нижней плавниковой каймы небольшую преанальную складку. Грудные плавники подвижные. В проходящем свете цвет глаз интенсивно черный, а в падающем они имеют бирюзовую окраску, с металлическим блеском. Головной отдел и передняя часть тела пигментированы рассеянным зеленым (или бирюзовым) пигментом. Перитониум пигментирован двумя рядами меланофоров и гуанофорами, придающими его поверхности серебристоголубой или серебристо-бирюзовый цвет, что в совокупности с окраской тела может играть защитную функцию, маскируя предличинок в зарослях водных макрофитов. Общий характер пигментации тела новорожденных предличинок $H$. octogrammus на перитонеуме, дорзальном и вентральном рядах меланофор, окраски головы и передней части туловища рассеянным зеленым (или бирюзовым) пигментом вполне соответствует видовому описанию в литературе (Горбунова, 1962; Kendall, Vinter, 1984; Антоненко, Гнюбкина, 2001).

Вместе с тем были выявлены и особенности пигментации предличинок бурого терпуга северной части Охотского моря от описанных в литературе Горбуновой (1962) и Антоненко и Гнюбкиной (2001) ровесников вида из Японского моря. Ни у одной из просмотренных нами предличинок бурого терпуга мы не обнаружили в хвостовом отделе верхнебоковой ряд меланофоров, а по нижнему краю хорды, вдоль которой должен был бы рас- 

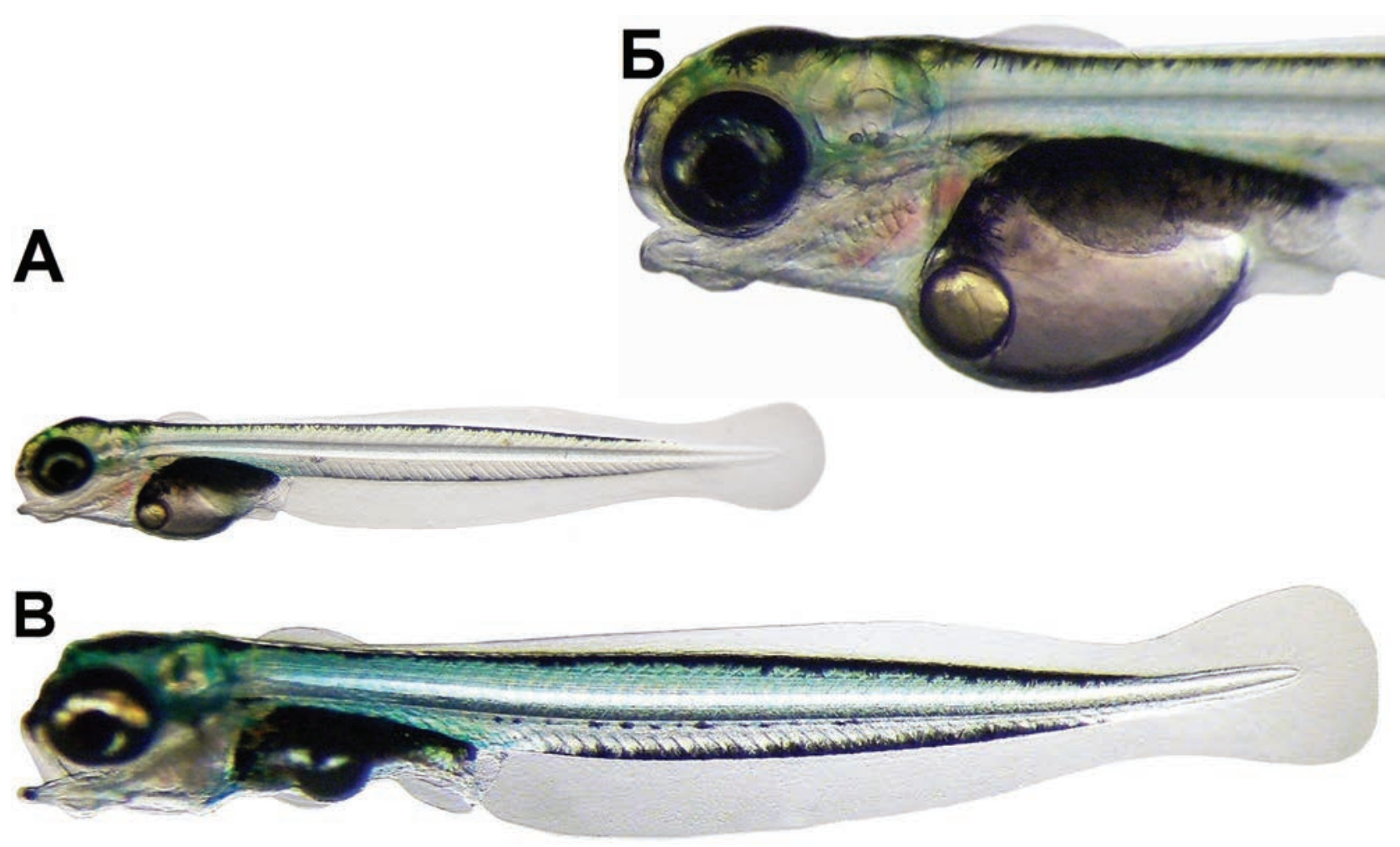

Puc. 5. Постэмбриональное развитие бурого терпуга северной части Охотского моря: А, Б - только что вылупившаяся предличинка; В - личинка в возрасте 5 сут

Fig. 5. Postembryonic development of the masked greenling in the northern part of the Sea of Okhotsk: A, $\mathbf{6}-$ newly hatched prelarva; $\mathbf{B}$ - larva, 5 days of age

полагаться описанный этими авторами нижнебоковой пигментный ряд, имелись только 1 , реже 2 меланофоры.

Поведенческие особенности предличинок бурого терпуга были во многом сходны с описанными нами ранее у пятнистого терпуга. Несмотря на функциональную готовность к активному плаванию (сравнительно крупные размеры и подвижные грудные плавники), они с момента вылупления и в течение этапа эндогенного питания характеризовались слабой активностью, находясь у дна вне зависимости от освещенности. В аквариальных условиях нашего эксперимента личинки бурого терпуга перешли на этап экзогенного питания к концу 5-х сут при размерах TL 8.74 мм (8.14-9.26 мм) и SL 8.21 мм (7.638.86 мм). У таких личинок произошла полная резорбция желточного мешка и жировой капли. Печень сместилась на латеральную сторону. Желточное кровообращение редуцируется, и кровеносная система становится дефинитивной. В пищеварительном тракте происходит развитие желудка, а рост дифференцировавшейся из общего кишечного тракта средней кишки приводит к образованию кишечной петли, наблюдаются периодические сокращения стенки прямой кишки в районе ануса. Преанальная складка сохраняется. Пигментация личинок рассеянным зеленым или бирюзовым пигментом усиливается, особенно в верхней части головного отдела, вдоль спины и верхнего края желудочно-кишечного тракта. Хорошо сформирован нижнебоковой пигментный ряд, образуемый 13-17 меланофорами разной величины. Верхнебоковой пигментный ряд продолжает отсутствовать. Усиление защитной окраски, образование плавательного пузыря и наполнение его газом обеспечивают личинкам возможность свободно передвигаться или находиться в покое на всех горизонтах аквариума.

Дальнейшие наблюдения были завершены, и все оставшиеся после эксперимента личинки бурого терпуга выпущены в акваторию бух. Нагаева.

\section{ЗАКЛЮЧЕНИЕ}

В ходе проведенных экспериментальных работ получены первые данные о характеристиках икры и подробно исследованы сроки прохождения этапов и основных стадий эмбрионального и раннего постэмбрионального развития бурого терпуга, обитающего в Тауйской губе северной части Охотского моря. Исследованиями было установлено, что при средней температуре $11.5^{\circ} \mathrm{C}$ для полного завершения периода эмбрионального развития требуется 33 сут и 11 ч при необходимой сумме принятого тепла $9417{ }^{\circ} \mathrm{C} / ч$, 
что превышает аналогичные показатели у пятнистого терпуга. Такая задержка связана с большей, чем у пятнистого терпуга, продолжительностью VI и VII этапов развития. Только что освободившиеся от оболочки яиц предличинки пятнистого терпуга имеют общую длину TL 7.15-8.06 мм (в среднем $7.77 \pm 0.06$ мм) и длину от начала рыла

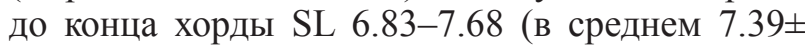
0.06 мм). В сравнительном плане они крупнее своих ровесников из других районов ареала. В аквариальных условиях переход на этап экзогенного питания происходит к концу 5-х сут при размерах TL 8.74 мм (8.14-9.26 мм) и SL 8.21 мм (7.63-8.86 мм).

Наряду с показателями размеров только что вылупившихся предличинок бурого терпуга, его региональные особенности проявляются в слабом развитии пигментации черными меланафорами боковых сторон тела. В течение первых 5 дней развивается лишь нижнебоковой ряд меланафоров.

Авторы выражают признательность сотруднику ИБПС ДВО РАН А. Е. Щербакову за оказанную техническую помощь в сборе производителей $H$. octogrammus и транспортировке икры к месту стационарных наблюдений.

\section{ЛИТЕРАТУРА}

Антоненко Д. В., Гнюбкина В. П. Некоторые особенности раннего онтогенеза бурого Hexagrammos octogrammus и пятнистого H. stelleri терпугов из залива Петра Великого (Японское море) // Вопросы ихтиологии. 2001. Т. 41, № 6. С. 799-803.

Антоненко Д. В., Пущина О. И. Основные черты биологии терпуговых рыб рода HEXAGRAMMOS в заливе Петра Великого (Японское море) // Известия ТИНРО. 2002. Т. 131. С. 164-178.

Горбунова Н. Н. Размножение и развитие рыб семейства Терпуговых (Hexagrammidae) // Тр. Ин-та океанологии АН СССР. 1962. Т. 59. С. 118-182.

Кауфман 3. С. Эмбриология рыб. Москва : Агропромиздат, 1990. $271 \mathrm{c}$.

Линдберг Г. У., Красюкова З. В. Рыбы Японского моря и сопредельных частей Охотского и Желтого морей. Ленинград : Наука, 1987. Ч. 5. 525 с.

Макеева А. П. Эмбриология рыб. Москва : Изд-во МГУ, 1992. $216 \mathrm{c}$.

Рутенберг Е. П. Обзор рыб семейства терпуговых (Hexagrammidae) // Тр. Ин-та океанологии АН СССР. 1962. T. 59. C. 2-100.

Федоров В. В., Черешнев И. А., Назаркин М. В., Шестаков А. В., Волобуев В. В. Каталог морских и пресноводных рыб северной части Охотского моря. Владивосток : Дальнаука, 2003. 204 с.

Черешнев И. А., Волобуев В. В., Хованский И. Е., Шестаков $A$. В. Прибрежные рыбы северной части Охотского моря. Владивосток : Дальнаука, 2001. 197 с.

Черняев Ж. А. Вертикальная камера для наблюдения за развитием икры лососевидных рыб // Вопросы ихтиологии. 1962. Т. 2. Вып. 3. С. 457-462.
Черняев Ж. А. Особенности раннего кроветворения у эмбрионов байкальского омуля и сига // Там же. 1964. Т. 44. Вып. 4 (33). С. 762-764.

Шестаков А. В., Грунин С. И. Биология бурого терпуга Hexagrammos octogrammus Pallas, 1810 Тауйской губы Охотского моря // Вестник СВНЦ ДВО РАН. 2018. № 2. C. 101-106.

Шестаков А. В., Назаркин М. В. Первые данные по биологии пятнистого Hexagrammos stelleri и бурого H. octogrammus терпугов Тауйской губы Охотского моря // Вопросы ихтиологии. 2006. Т. 46. Вып. 5. C. 711-714.

Юсупов Р. Р., Юсупов Рус. Р. Эмбриональное и раннее личиночное развитие пятнистого терпуга Hexagrrammos stelleri (Hexagrammidae) северной части Охотского моря // Известия ТИНРО. 2019а. Т. 199. C. $141-151$.

Юсупов Р. Р., Юсупов Рус. Р. О развитии перибластического синуса в эмбриогенезе бурого Нехаgrammos octogrammus и пятнистого $H$. stelleri терпугов (Scorpaeniformes: Hexagrammidae) // Онтогенез. 2019б. T. 50, № 5. C. 355-359.

Gomelyuk E. V., Leunov V. P. Changes in age-specific behavior and spatial structure of masked greenling Hexagrammos octogrammus (Hexagrammidae) // Envinomental Biology of Fishes. 1999. No. 54. P. 313-323.

Karen D.C., Munehara H., Kanamoto Z., Balanov A., Antonenko D., Bernardi G. Maintenance of species boundaries despite rampant hybridization between three species of reef fishes (Hexagrammidae): Implications for the role of selection // Biological Journal of the Linnean Society. 2007. No. 91. P. 135-147.

Kendall A. V. Jr., Vinter B. Development of hexagrammids (Pisces: Scorpaeniformes) in the northeastern Pacific Ocean // NOAA Tech Rep NMFS. 1984. No. 2. $44 \mathrm{p}$.

Mecklenburg C. W., Mecklenburg T. A., Sheiko B. A., Steinke D. Pacific Arctic Marine Fishes // CAFF Monitoring Ser. Rep. 2016. No. 23. 398 p.

Moser H. G. The early stages of fishes in the California Current Region. California COFI Atlas. No. $33 /$ Ed. by H. G. Moser Lawrence. Allen Press Inc., 1996. $1505 \mathrm{p}$.

Moyer J. T., Zaiser M. J. Social organization and spawning behavior of the pteroine fish Dendrochirus zebra at Miyaki-jima, Japan // Japanese Journal of Ichthyology. 1981. Vol. 28. P. 52-69.

Munehara H., Kanamoto Z., Miura T. Spawning behavior and interspecific breeding in three Japanese greenlings (Hexagrammidae) // Ichthyological Research. 2000. No. 47. P. 287-292.

Munehara H., Shimazaki K., Misima S. The Process of Oogenesis in Masked Greenling Hexagrammos octogrammus // Bulletin of the Faculty of Fisheries Hokkaido University. 1987. No. 38 (1). P. 27-33.

Quast J. C. Meristic variation in the Hexagrammid fishes // Fishery Bulletin. 1964. No. 63. P. 589-609.

Washington B. B., Moser H. G., Laroche W. A., Richards W. J., 1983. Scorpaeniformes: development, ontogeny and systematics of fishes // American Society of Ichthyologists and Herpetologists, Special Publication. 1. 405-428. 


\title{
EMBRYONIC AND EARLY LARVAL DEVELOPMENT OF THE MASKED GREENLING HEXAGRAMMOS OCTOGRAMMUS (SCORPAENIFORMES: HEXAGRAMMIDAE) IN THE NORTHERN PART OF THE SEA OF OKHOTSK
}

\author{
R. R. Yusupov, Rus. R. Yusupov \\ Institute of Biological Problems of the North, FEB RAS, Magadan
}

\begin{abstract}
The roe of Hexagrammos octogrammus from of the Northern part of the Sea of Okhotsk was incubated in an experiment. A detailed description of the morphology of the species development, from fertilization of eggs to the fry transition to external nutrition, accompanied by microphotographs of eggs and larvae fry in vivo, is given. It was established that the fertilized eggs of H. octogrammus from the northern part of the Sea of Okhotsk are $1.75 \mathrm{~mm}$ in diameter with fluctuations of 1.61$1.98 \mathrm{~mm}$. Hatching of embryos occurs after 33.5 days of incubation at an average temperature of $11.5^{\circ} \mathrm{C}$. Hatched yolk fry is $7.78 \mathrm{~mm}(7.15-8.06 \mathrm{~mm})$ of TL (Total length) and $7.39 \mathrm{~mm}(6.83-$ $7.68 \mathrm{~mm}$ ) of SL (Standard length). Upon reaching TL of $8.74 \mathrm{~mm}(8.14-9.26 \mathrm{~mm}$ ) and SL of $8.21 \mathrm{~mm}$ $(7.63-8.86 \mathrm{~mm})$, the fry switch to external feeding. The regional features of the masked greenling pigmentation in early ontogenesis are revealed.
\end{abstract}

Keywords: masked greenling Hexagrammos octogrammus, embryonic development, prelarva, larva, the Northern part of the Sea of Okhotsk.

\section{REFERENCES}

Antonenko, D. V., Gnyubkina, V. P., 2001. Some Features of the Early Ontogenesis of the Masked Greenling Hexagrammos octogrammus and the White-Spotted Greenling H. stelleri from Peter the Great Bay (Sea of Japan), Journal of Ichthyology. 41, 9, 761-765 [In Russian].

Antonenko, D. V., Pushchina, O. I., 2002. Main Biological Features of Greenlings (Genus Hexagrammos) in Peter the Great Bay (Japan Sea), Izvestiya TINRO. 131, 164-178 [In Russian].

Chereshnev, I. A., Volobuev, V. V., Khovansky, I. E., Shestakov, A. V., 2001. Coastal Fishes in the Northern Part of the Sea of Okhotsk, Vladivostok, Dalnauka [In Russian].

Chernyaev, Zh. A., 1962. Vertical Chamber for Monitoring the Development of Salmonid Eggs, Journal of Ichthyology. 2, 3, 457-462 [In Russian].

Chernyaev, Zh. A., 1964. Features of Early Hemopoiesis in Embryos of the Baikal Omul and Whitefish, Ibid. 4, 4, $762-764$ [In Russian].

Fedorov, V. V., Chereshnev, I. A., Nazarkin, M. V., Shestakov, A. V., Volobuev, V. V., 2003. Catalog of Marine and Freshwater Fishes in the Northern Part of the Sea of Okhotsk. Vladivostok, Dalnauka [In Russian].

Gomelyuk, E. V., Leunov, V. P., 1999. Changes in AgeSpecific Behavior and Spatial Structure of Masked Greenling Hexagrammos octogrammus (Hexagrammidae), Envinomental Biology of Fishes. 54, 313-323.

Gorbunova, N. N., 1962. Reproduction and Development of the Family Hexagrammidae, Trudy Instituta Okeanologiyi, AN SSSR. 59, 118-182 [In Russian].

Karen, D. C., Munehara, H., Kanamoto, Z., Balanov, A., Antonenko, D., Bernardi, G., 2007. Maintenance of Spe- cies Boundaries Despite Rampant Hybridization between Three Species of Reef Fishes (Hexagrammidae): Implications for the Role of Selection, Biological Journal of the Linnean Society. 91, 135-147.

Kaufman, Z. S., 1990. Fish Embryology. Moscow, Agropromizdat [In Russian].

Kendall, A. V. Jr., Vinter, B., 1984. Development of Hexagrammids (Pisces: Scorpaeniformes) in the Northeastern Pacific Ocean, NOAA Tech Rep NMFS. 2.

Lindberg, G. U., Krasyukova, Z. V., 1987. Fishes in the Sea of Japan and Adjacent Parts of the Sea of Okhotsk and the Yellow Sea. Leningrad, Nauka, 5 [In Russian].

Makeeva, A. P., 1992. Fish Embryology. Moscow, MSU [In Russian].

Mecklenburg, C. W., Mecklenburg, T. A., Sheiko, B. A., Steinke, D., 2016. Pacific Arctic Marine Fishes, CAFF Monitoring Series Report 23.

Moser, H. G., 1996. The Early Stages of Fishes in the California Current Region. California COFI Atlas, 33, Ed. H. G. Moser Lawrence. Allen Press Inc.

Moyer, J. T., Zaiser, M. J., 1981. Social Organization and Spawning Behavior of the Pteroine Fish Dendrochirus Zebra at Miyaki-Jima, Japan, Japanese Journal of Ichthyology. 28, 52-69.

Munehara, H., Kanamoto, Z., Miura, T., 2000. Spawning Behavior and Interspecific Breeding in Three Japanese Greenlings (Hexagrammidae), Ichthyological Research. 47, 287-292.

Munehara, H., Shimazaki, K., Misima, S., 1987. The Process of Oogenesis in Masked Greenling Hexagrammos octogrammus, Bulletin of the Faculty of Fisheries Hokkaido University. 38, 1, 27-33. 
Quast, J. C., 1964. Meristic Variation in the Hexagrammid Fishes, Fishery Bulletin. 63, 589-609.

Rutenberg, E. P., 1962. Review of Fish of the Family Hexagrammidae, Trudy Instituta Okeanologiyi AN SSSR. 59, 2-100 [In Russian].

Shestakov, A. V., Grunin, S. I., 2018. Biology of the Masked Greenling Hexagrammos octogrammus Pallas, 1810 in the Tauysk Bay of the Sea of Okhotsk, Bulletin of the North-East Science Center FEB RAS. 2, 101-106 [In Russian].

Shestakov, A. V., Nazarkin, M. V., 2006. On the Biology of the White-Spotted Greenling Hexagrammos stelleri and the Masked Greenling H. octogrammus (Hexagrammidae) from the Tauysk Bay of the Sea of Okhotsk, Journal of Ichthyology. 46, 5, 711-714 [In Russian].
Washington, B. B., Moser, H. G., Laroche, W. A., Richards, W. J., 1983. Scorpaeniformes: Development, Ontogeny and Systematics of Fishes. American Society of Ichthyologists and Herpetologists, Special Publication. 1, 405-428.

Yusupov, R. R., Yusupov, Rus. R., 2019. Embryonic and Early Larval Development of the White-Spotted Greenling Hexagrammos stelleri (Scorpaeniformes: Hexagrammidae) from the Northern Okhotsk Sea, Izvestiya TINRO. 199, 141-151 [In Russian].

Yusupov, R. R., Yusupov, Rus. R., 2019. On the Development of Periblastic Sinus in Embriogenesis of Masked Hexagrammos octogrammus and White-Spotted H. stelleri Greenlings (Scorpaeniformes: Hexagrammidae), Russian Journal of Developmental Biology. 50, 5, 355-359 [In Russian]. 